\title{
Ending Child Marriage in Nigeria: The Maternal and Child Health Country-Wide Policy
}

\section{Hawa Iye Obaje, Chinelo Grace Okengwu, Aimable Uwimana, Henry Kanoro Sebineza, Chinonso Emmanuel Okorie}

University of Global Health Equity, Bill and Joyce Cummings Institute of Global Health, Butaro, Burera, Rwanda

http://doi.org/10.38126/JSPG170116

Corresponding author: obajehawa@gmail.com

Keywords: child marriage; girls; early marriage; SDG 3; global health; equity; Nigeria

\begin{abstract}
Executive Summary: Reduction in child marriage is highly correlated with a decline in maternal and child morbidity and mortality. Nigeria has taken a step to reduce child marriage through the Child Rights Act; however, 11 states in the Northeast and Northwest are yet to implement these laws despite the documented benefits. Estimates predict that a $70 \%$ reduction of maternal deaths can be achieved by a $10 \%$ reduction in child marriage. Additionally, the $\$ 7.6$ billion lost in earning and productivity of human capital from child marriage annually can be averted. A reduction in child marriage can also decrease violence against girls and improve educational level attainment. We propose that the Nigerian government should enact the Maternal and Child Health Country-wide Policy to give a national security treatment to maternal and child health matters. It will ensure that policies passed at the federal level with the potential to reduce maternal and child mortality can be automatically adopted nationwide.
\end{abstract}

\section{Statement of issue}

Nigeria has a child marriage prevalence of $64 \%$ with an estimate of twenty-two million child marriages that lead to a massive increase in maternal and child morbidity and mortality (Ujam 2019; Yaya, Odusina, and Bishwajit 2019). In comparison with women above 20 years old, girls 10-14 years of age are five to severn times more likely to die from childbirth while girls 15-19 years of age are twice as likely to die from childbirth (Nour 2006). When they do not die from childbirth, $70 \%$ of child brides $10-19$ years old suffer from complications in childbirth - obstructed labor, postpartum hemorrhage, obstetric fistula, and more. (Adedokun, Adeyemi, and Dauda 2016). Also, the risk of delivering preterm and low birth weight infants are $35-55 \%$ higher in girls $15-18$ years compared to girls above 18 years (Nour 2006). Similarly, mothers younger than 20 years old experience a $73 \%$ higher incidence of infant mortality (Girls Not Brides 2013; Nour 2006). Moreover, a strong correlation between maternal mortality rate and child marriage prevalence exists as a $10 \%$ reduction in child marriage could be associated with a $70 \%$ reduction in a country's maternal mortality rates (Raj and Boehmer 2013).

In Nigeria, the loss suffered in earnings and productivity of human capital due to child marriage costs the country $\$ 7.6$ billion annually (World Bank 2017). The reduction in the number of child brides aligns with the United Nations' (UN) sustainable development goals (SDG) three and five (SDG 3 and SDG 5)-reducing maternal mortality and eliminating violence against girls and child marriage, respectively (UN 2019). 
The Child Rights Act of Nigeria, which protects girls from child marriage, has the potential to transform the maternal mortality trend. However, it has not been implemented across every state in Nigeria due to state autonomy. The government should enact the Maternal and Child Health Country-wide Policy. This policy proposes treating maternal and child health matters as issues of national security as matters of national security are on the exclusive legislative list of the federal government and as such take precedence over state autonomies.

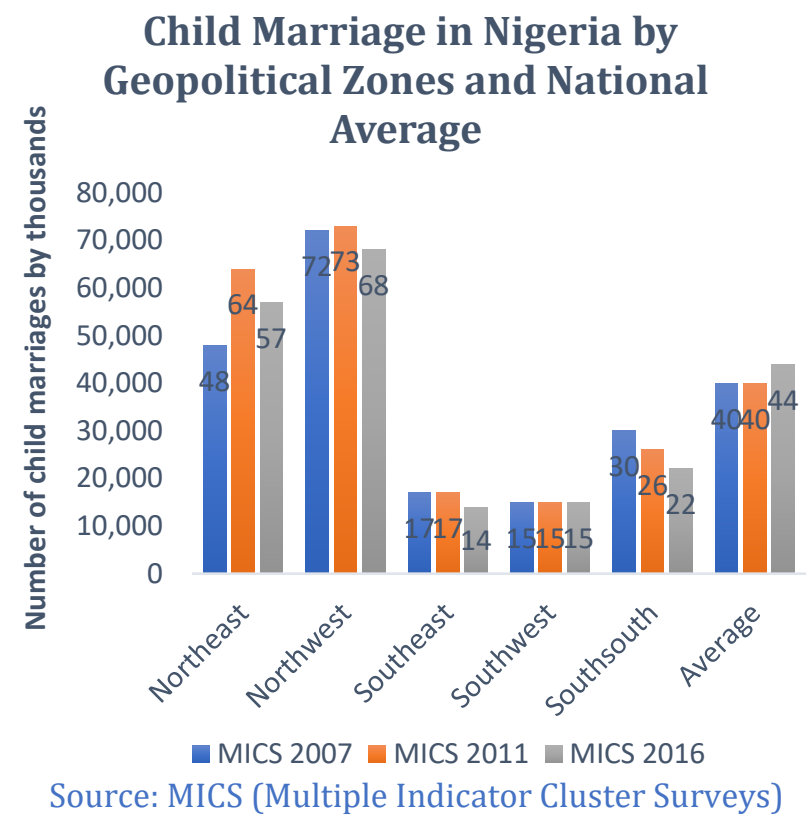

Figure 1: This figure shows how child marriage prevalence is distributed across geopolitical zones and the national average in 2007, 2011, and 2016.

\section{Political and legal status}

Nigeria operates a three-tiered system of government-legislative, executive, and judicial. Although the federal legislations have the force of law in the entire country, the states still have legislative autonomy (i.e. laws have to be domesticated into each state for it to be effective except if they conflict with the constitution) (Federal Government of Nigeria 1999). Nigeria's tripartite legal system-the simultaneous implementation of civil, customary, and Islamic law-prevents the federal government from having control over marriages conducted under customary or Islamic law (Braimah 2014). Therefore, without the domestication of the Child Rights Act in the non-implementing states which are governed by customary and Islamic laws, the Child Rights Act cannot be operationalized.
The Child Rights Act that has been enacted to guard against child marriage in Nigeria has been particularly weak with respect to enforcement. Findings show that eleven out of thirty-six states (grouped under Northeast (NE) and Northwest (NW) in Figure 1) have not implemented the Child Rights Act because they have internal laws (mostly customary and sharia laws) that allow marriage for girls as young as 11 years old. The autonomy of states, as recognized by the constitution, have aided this lack of consistency in implementation. However, the Federal Government and all stakeholders can embark on the goal to ensure that the provisions of the Child Rights Act are adopted and enforced nationwide.

\section{Stakeholders}

Child and anti-child marriage have strong and influential stakeholders. Stakeholder roles vary according to geopolitical zones in Nigeria. For instance, in the NW, grandparents have authority over when and who child brides marry, parents come secondary with often very limited choice left to the girls. However, traditional and religious leaders have influence over parents and grandparents for or against child marriage depending on their beliefs. Whereas in the NE, while the parents and religious rulers play similar roles as in the NW, the grandparents have lesser authority and girls have higher freedom of choice. However, the religious leaders tend to discourage the practice, but parents are the final arbiters (The Federal Ministry of Women Affairs and Social Development 2016).

These stakeholders can be grouped based on the level of interest and power they have to influence changes; however, those with low interest have the potential to increase their interest based on engagements. For example, the Nigerian lawmakers, Ministries of Health, Women Affairs and Social Development, and parents are stakeholders with high power and variable interest. Those with high power and high interest are grandparents, men who marry children, and traditional and religious leaders. Meanwhile, interest groups like girls, Girls not Brides, Sexual Offences Awareness and Victims Rehabilitation Initiatives can be classified as having low power and high interest. Although the Medical Women Association of Nigeria can be placed in the low power and low-interest stakeholders, they have the potential of increasing their interest based on the maternal morbidity and mortality impact (The 
Federal Ministry of Women Affairs and Social Development 2016).

Potential issues can arise between various stakeholder groups due to clashes in belief and values and can influence policy implementation. In the formulation of this policy, it is essential to engage stakeholders in activities, dialogue and decisionmaking while also implementing financial and nonfinancial strategies to build synergy and strengthen alliance among stakeholders. The engagements of all stakeholders and execution of strategies will help move the policy implementation forward through advocacy and activism.

\section{Policy options}

\section{i. Option 1: Enact the Maternal and Child Health} Country-wide Policy

The "Maternal and Child Health Country-wide Policy" proposes the treatment of maternal and child health issues as matters of national security, which must be given national priority as such. For instance, in 2015 alone, 58,000 Nigerian women died from pregnancy and childbirth complications compared to 13,000 deaths due to the Boko Haram insurgency (a jihadist armed rebellion group fighting against the government of Nigeria which began in 2009) between 2010 and 2015. However, the latter was a national priority (World Health Organization 2019; Ogunlesi 2018). Although there is a dearth of disaggregated data on child brides' maternal mortality numbers in Nigeria, studies have highlighted a significant correlation between child marriage and maternal mortality and morbidity (Raj and Boehmer 2013; Girls Not Brides 2013). Severe effects of child marriage on maternal health has been evident before pregnancy as child brides are forced to withdraw from school which predisposes them to psychological distress and domestic violence, thereby contributing to adverse health outcomes during and after pregnancy (Yaya, Odusina, and Bishwajit 2019; Walker 2019).

\section{Advantages}

- This policy will contribute to reducing the maternal and child mortality ratio in Nigeria which currently stands at 917 deaths per 100,000 and 119.9 deaths per 1,000 live births, respectively. Hence, it works towards achieving the SDG 3 target of 70 deaths per
100,000 and 25 per 1000 live births for mothers and the child, respectively (World Bank 2019; Barredo et al. 2015).

- The implementation of this policy would give space for Acts/Bills on other issues affecting maternal and child health to be implemented.

\section{Disadvantage}

- It will suffer opposition from states and religious groups that support child marriage.

ii. Option 2: Extend free education to the secondary level for girls

This policy proposes that all girls in the NE and NW should attend primary and secondary education on scholarships. This is because girls in these regions are educationally deprived with net school attendance of $47.7 \%$ in the NE and $47.3 \%$ in the NW (UNICEF 2013). Although there is a policy on free and compulsory primary education for children in Nigeria, it is not equally and fully being enforced in all states (UNICEF 2013). Primary education is vital but not long enough to keep children out of child marriage; however, every additional year of secondary school education decreases the likelihood of marriage before the age of 18 by $5 \%$ or more (World Bank, 2017). Also, girls rescued from child marriage even after having a baby should be reintegrated into primary and secondary education alongside peers, similar to the Jamaican reintegration policy for school-aged mothers and South African Schools Act 108 (Ngabaza and Shefer, 2013; Kennedy, 2017).

\section{Advantages}

- Reduce vulnerability to marital and sexual exploitation.

- Promotion of gender and regional equity within the country.

\section{Disadvantages}

- This policy focuses only on female children from the NE and NW regions.

- Sustainability of the policy is dependent on continuous funding from the government or donor agencies.

\section{iii. Option 3: Develop the Girl Rescue Emergency Plan}

We propose the introduction of an effective proactive reporting plan for the protection of girls from child marriage. This plan will entail establishing toll-free child brides rescue call-in services coordinated at the 
Federal and State offices of the Ministry of Women Affairs and Social Development. Although in communities, child marriage is a controversial topic and acceptance differs by families. This rescue call-in services will be linked to newly developed community-based support groups to provide a safe space for girls and will utilize family engagement to educate families on child rights. Community members can call in to report cases of imminent child marriages, and child brides can also report sexual or physical violence against them.

This whistle blowing plan involves partnership across stakeholders to ensure a holistic process in reducing child marriage as similar to the Isange initiative for gender-based violence in Rwanda (Friends of Imbuto Foundation 2020).

\section{Advantages}

- Rescues girls from getting married against their will and improves the reporting of sexual and physical violence.

- Social support groups create opportunities for self-development, friendships, and psychosocial assistance.

\section{Disadvantages}

- Girls may not readily have access to phones.

- Reporting may increase violence against girls from their husband, family members, and relatives.

\section{Policy recommendation}

We recommend that the government adopt Option 1, Enact the Maternal and Child Health Country-Wide Policy. This policy has the advantage of limiting state autonomy to determine the fate of maternal and child health in the country. We anticipate the potential lack of political will and backing for this policy option. However, liaison with key stakeholders-girls, parents, grandparents, Girls Not Brides Nigeria, Nigerian lawmakers and Ministry of Health-is crucial to obtaining support for the enactment of this policy. These stakeholders can influence political backing by amplifying the impact of child marriage on the physical and mental wellbeing and its importance as a national security item. It has already been established that child marriage has been a significant driver of maternal and child morbidity and mortality globally (Girls Not Brides 2013). Therefore, the Maternal and Child Health Country-wide Policy can save many lives by presenting maternal and child health as a matter of national security. The government of Nigeria should enact this policy to aid the improvement of child rights, reduction of maternal and child morbidity and mortality towards achieving the targets of SDG 3 and 5.

\section{References}

Adedokun, Olaide, Oluwagbemiga Adeyemi, and Cholli Dauda. 2016. "Child Marriage and Maternal Health Risks among Young Mothers in Gombi, Adamawa State, Nigeria: Implications for Mortality, Entitlements and Freedoms." African Health Sciences 16(4):986-99. https://doi.org/10.4314/ahs.v16i4.15.

Barredo, Lauren, Irene Agyepong, Gordon Liu, and Srinath Reddy. 2015. "Ensure Healthy Lives and Promote Well-Being for All at All Ages." UN $\begin{array}{llll}\text { Chronicle } & 51 & \text { (4): } & 9-10 .\end{array}$ https://doi.org/10.18356/3bfe3cfa-en.

Braimah, Tim S. 2014. "Child Marriage: The Danger within Part 1 Section 61 of the 1999 Constitution and Its Barrier to Legally Protect Children Against Child Marriage in Nigeria." SSRN Electronic Journal, 474-88. https://doi.org/10.2139/ssrn.2309374.
Federal Government of Nigeria. 1999. "Constitution of the Federal Republic of Nigeria 1999 Arrangement of Sections Chapter I General Provisions Part I Federal RepublicofNigeria,"1169.

https://publicofficialsfinancialdisclosure.worl dbank.org/sites/fdl/files/assets/law-libraryfiles/Nigeria Constitution 1999 en.pdf.

Friends of Imbuto Foundation. 2020. "ABOUT US OUR STORIES IMPACT GET INVOLVED Watch Our Latest Video 'TANTINE APP' COULD REDUCE," 12.

Girls Not Brides. 2013. "Talking Points: Child Marriage and Maternal and Child Health," 3. https://www.girlsnotbrides.org/wpcontent/uploads/2014/04/Child-marriage-andmaternal-health-Girls-Not-Brides-Updated-27May-2013.pdf. 
Kennedy, Dasmine. 2017. “The Jamaican Reintegration Policy for School-Aged Mothers_ A Step in the Right Direction_," 2015-18.

Nour, Nawal M. 2006. "Health Consequences of Child Marriage in Africa." Emerging Infectious Diseases $12 \quad$ (11): 1644-49. https://doi.org/10.3201/eid1211.060510.

Ogunlesi, Tolu. 2018. "Have over 13, 000 People Been Killed in Nigeria' s Insurgency? The Claim Is Broadly Correct Killings by Boko Haram and the Nigerian Military."

Raj, Anita, and Ulrike Boehmer. 2013. "Girl Child Marriage and Its Association With National Rates of HIV, Maternal Health, and Infant Mortality Across 97 Countries." Violence Against Women 19 (4): 536-51. https://doi.org/10.1177/1077801213487747.

The Federal Ministry of Women Affairs and Social Development. 2016. "National Strategy to End Child Marriage in Nigeria." Unicef. https://www.unicef.org/india/what-we-do/endchild-marriage.

UNICEF. 2013. "Education - UNICEF Nigeria." https://www.unicef.org/nigeria/education

Ujam, Nonyelum. 2019. "Child Marriage in Nigeria: Wedded to Poverty." YaleGlobal Online, 1-8. https://yaleglobal.yale.edu/content/childmarriage-nigeria-wedded-poverty.

UN. 2019. “\#Envision2030: 17 Goals to Transform the World for Persons with Disabilities | United Nations Enable." The UN, 1-4. https://www.un.org/development/desa/disabilit ies/envision2030.html.
Walker, Judith-Ann. 2019. "Building Resilience and Resistance to Child, Early, and Forced Marriage through Acquiring Skills Findings from Implementation Research in Nigeria Building Resilience and Resistance to Child, Early, and Forced Marriage through Acquiring Skills: Findings Fr." Global Economy and Development at Brookings, $1-50$. https://www.brookings.edu/wpcontent/uploads/2019/08/Findings-fromImplementation-Research-in-Nigeria-FINAL.pdf.

World Bank. 2017. "Nigeria - Under-Five Mortality Rate 119.9," 1-2.

World Bank. 2019. "Nigeria - Maternal Mortality Ratio," 1-2.

World Health Organization. 2019. "Maternal Health in Nigeria: Generating Information for Action." Sexual and Reproductive Health, 1-3. https://www.who.int/reproductivehealth/mater nal-health-nigeria/en/.

Yaya, Sanni, Emmanuel Kolawole Odusina, and Ghose Bishwajit. 2019. "Prevalence of Child Marriage and Its Impact on Fertility Outcomes in 34 SubSaharan African Countries." BMC International Health and Human Rights 19 (1): 1-11. https://doi.org/10.1186/s12914-019-0219-1

Hawa I. Obaje holds an MSc in Global Health Delivery from the University of Global Health Equity. Hawa has experience in the field of research, sexual and reproductive health in Nigeria and Rwanda. She is passionate about advancing the health and rights of vulnerable populations.

Chinelo G. Okengwu is a medical doctor with a wealth of experience in Child Health and is passionate about improving health care delivery among vulnerable populations, especially for disadvantaged children. She recently graduated from the University of Global Health Equity with a master's degree in Global Health Delivery.

Aimable Uwimana holds an MSc in Global Health Delivery from the University of Global Health Equity and a BA in Healthcare Management at Southern New Hampshire University. Aimable has experience in the field of research and non-communicable diseases education in Rwanda. He is passionate about addressing the social determinants of health, especially among vulnerable communities.

Henry K. Sebineza is from the Democratic Republic of the Congo and is passionate about equity and social justice. He holds a Bachelor of Arts in Healthcare Management with a concentration in Global Perspectives from Southern New Hampshire University through Kepler University Program and an MSc in Global Health Delivery from the University of Global Health Equity. 
Chinonso E. Okorie is a Nigerian humanitarian medical doctor and holds a Master of Science in Global Health Delivery graduate from the University of Global Health Equity, Rwanda. He writes from his passion for serving marginalized, poor, and vulnerable population groups with social justice.

\section{Acknowledgements}

We would like to thank our professor and lecturers Dr. Zahirah McNatt, Enock Ruwanuza and Chisom Nwaneri for teaching us the Health Policy and Political Economy Course, their unwavering support and guidance throughout this process. Also, to our lawyer friends Nuradeen Abdulmumim Esq, Darlington Friday Okeoga Esq, and Mumuni Damilola Esq, we appreciate your critical review efforts.

\section{Disclaimer}

The authors wrote this work; any parts quoted from other sources have been referenced without exception. 